\section{BMJ Open \\ Respiratory \\ Research}

\title{
Patients' practices and experiences of using nebuliser therapy in the management of COPD at home
}

\author{
B Alhaddad, ${ }^{1}$ F J Smith, ${ }^{2}$ T Robertson, ${ }^{3}$ G Watman, ${ }^{3}$ K M G Taylor ${ }^{2}$
}

To cite: Alhaddad B, Smith FJ, Robertson T, et al. Patients' practices and experiences of using nebuliser therapy in the management of COPD at home. BMJ Open Resp Res 2015;2:e000076. doi:10.1136/bmjresp-2014000076

Received 18 December 2014 Revised 29 January 2015 Accepted 4 February 2015

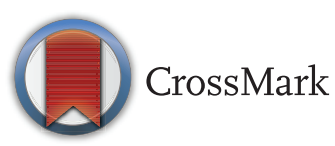

${ }^{1}$ Public Authority for Applied Education \& Training, College of Health Sciences,

Shuwaikh, Kuwait

${ }^{2}$ UCL School of Pharmacy, London, UK

${ }^{3}$ NHS Harrow CCG, London, UK

\section{Correspondence to} Professor K M G Taylor; kevin.taylor@ucl.ac.uk

\section{ABSTRACT}

Background and aim: How patients use their nebulisers at home is vital to ensure effective treatment and optimal health outcomes for patients with chronic obstructive pulmonary disease (COPD). The aim of the study was to identify the practicalities and problems associated with nebuliser use by patients with COPD at home, which may impact on the safety and effectiveness of therapy.

Design and setting: A cross-sectional descriptive study in which participants were recruited from two levels of care: primary care, involving $38 \mathrm{GP}$ practices in North West London, and intermediate care with a major acute hospital.

Method: In-depth interviews were conducted with a representative sample of 50 patients with COPD using nebulisers in their home, recruited from general practice populations and at hospital discharge. A checklist was used to record activities and patients demonstrated use of their nebuliser. Qualitative procedures were employed to identify the range of problems experienced with nebuliser use.

Results: A wide range of practical issues was identified at all stages: problems prior to nebulisation: setting up equipment, lack of instructions, manual dexterity and time required. Problems during medication administration: inhalation technique, duration of nebulisation and understanding how to achieve optimal efficacy. Problems post-administration: inadequate cleaning of nebuliser components, access to accessories and use of damaged parts or self-repairs. Other problems included noise, weight and non-portability of equipment.

Conclusions: Patients with COPD using nebulisers at home experienced problems with all aspects, many of which may be anticipated to compromise clinical outcomes. Healthcare providers should be aware of these problems to effectively support patients with COPD with the use of their nebulisers at home.

\section{INTRODUCTION}

Nebuliser therapy is frequently prescribed for management of chronic obstructive pulmonary disease (COPD) in the home, and may be valuable for patients who are elderly, have difficulties with hand-held inhalers,

\section{KEY MESSAGES}

Patients with chronic obstructive pulmonary disease (COPD) using nebulisers at home experienced problems at all stages, including problems prior to nebulisation: setting up equipment, lack of instructions, manual dexterity and time required. Problems during medication administration: inhalation technique, duration of nebulisation and understanding how to achieve optimal efficacy. Problems postadministration: inadequate cleaning of nebuliser components, access to accessories and use of damaged parts or self-repairs. Other problems included noise, weight and non-portability of equipment. Healthcare providers should be aware of these problems to effectively support patients with COPD with the use of their nebulisers at home.

require high treatment doses or have comorbidities. ${ }^{12}$ About half of the patients who remain breathless despite high-dose bronchodilators delivered by pressurised metered dose inhalers (pMDIs) or dry powder inhalers (DPIs), derive benefits from domiciliary nebuliser therapy. ${ }^{3}$ Studies have shown that nebuliser therapy has a role in the management of severe COPD in the community, ${ }^{4-6}$ with a positive impact on quality of life.

The correct use of inhaler devices is crucial in achieving successful therapy. ${ }^{7}$ The use of inhaler devices poses challenges for older patients, ${ }^{2} 8$ and has been linked to suboptimal health outcomes. While pMDI and DPI use has been extensively studied, ${ }^{2}{ }^{9-12}$ nebuliser use has attracted less attention. In the few studies investigating nebuliser use by patients with COPD in the home, problems have been reported with assembling nebuliser equipment ${ }^{13}$ and gauging how long to nebulise fluids. ${ }^{14}$ Inadequate cleaning of equipment after use has been highlighted in several studies. ${ }^{13-18}$ While a number of problems have been identified, a comprehensive study of home nebuliser use, from the perspectives of patients with COPD, to identify 
potential contributory factors that may lead to treatment failure, has not been undertaken.

The aim of this study was to examine nebuliser use for the daily management of COPD from the perspectives of patients. Mixed methods were employed, with collection of data in patients' own homes to reflect their natural settings, and provide an understanding of difficulties and problems they experience. This study was designed to highlight problems and practices that may result in suboptimal clinical outcomes across all stages of nebuliser use. The study will inform the development of services to support this patient group in achieving more effective management of their condition.

\section{METHODS}

Data were collected in semistructured interviews in patients' homes. Participants were recruited from two settings: a primary care setting comprising 38 GP surgeries, and an intermediate care setting (healthcare and rehabilitation team located at a major acute hospital). This enabled inclusion of patients whose disease was being adequately managed in the community, and those recently admitted to hospital for an exacerbation, suggestive of treatment failure. Eligible patients had a confirmed diagnosis of COPD and were prescribed nebules/Respules and/or Combivent (ipratropium and salbutamol) for use with a nebuliser at home. All patients eligible to participate were identified through the collaborators at the study sites. All potential participants were then reviewed by their treating doctors, who identified those they believed should be excluded because of mental health problems or severe cognitive impairment, or because they were unwell or had other serious illness. An invitation pack was sent to all eligible patients. Home interviews were arranged with those patients who returned a reply slip indicating willingness to participate. Informed consent was obtained prior to data collection.

The interview schedule comprised structured and open questions to identify and explore the range of experiences associated with nebuliser use in the home. All participants were asked to describe and demonstrate how they set up and operated their nebuliser system, while the researcher observed and recorded their technique using a checklist developed for this study. They were asked how they assembled the different components of the nebuliser, diluted drug fluid (if required), mixed drug formulations (if two formulations were used), filled fluid into the nebuliser reservoir and how they operated the compressor. The patients were also asked to demonstrate how they fitted the facemask on their face or used the mouthpiece and inhaled their nebulised dose. They were asked to demonstrate and describe how they dismantled, cleaned and dried nebuliser parts after nebulisation, and to indicate the frequency with which they replaced nebuliser parts and serviced the compressor. Patients were observed by the researcher while they demonstrated their cleaning and drying techniques. In addition to structured question and check lists, open questions relating to all aspects of nebuliser use enabled detailed discussion of patients' experiences and difficulties. The checklist and all instruments were piloted and revised in collaboration with the study team prior to the collection of data. Interviews were audio recorded and transcribed verbatim. Structured data were entered into SPSS for descriptive analyses. For data gathered in response to open questions, analysis was facilitated by using the FRAMEWORK software (NatCen). This enabled systematic application of qualitative procedures (especially a themed approach employing constant comparison), such that concepts remain grounded in the data.

\section{RESULTS}

\section{Characteristics of participants}

Of 180 patients who were sent invitation packs, 83 returned the reply slip, of whom 60 agreed to take part. The collection of data continued until the target number of 50 patients was achieved. The participants comprised 21 male and 29 female patients with a mean age of 71 years. Thirty-two lived alone and 15 were assisted by a family carer. Forced expiratory volume in $1 \mathrm{~s}\left(\mathrm{FEV}_{1}, \%\right.$ predicted) from patients' medical records was used to indicate severity of disease. For 24 patients, disease was severe $(30-49 \%)$, for 16 , moderate (50$79 \%)$ and for 10 patients, mild $(\geq 80 \%)$. The mean duration of nebuliser use was 9 years (range 6 months to 30 years). Patients were using 12 different models/ makes of jet nebuliser in combination with 1 of 12 makes/models of compressor, or 1 of 5 ultrasonic or mesh nebulisers.

\section{The use of nebuliser therapy in the home}

Table 1 shows the deviations from correct nebuliser use as observed by the researcher. Those deviations that may compromise drug delivery are highlighted. The data from the observations are considered, combined with the problems and difficulties reported by patients in the interviews, with themes identified from the patients' accounts described in relation to specific activities. Findings are presented in relation to three stages: prior to inhaling the dose, inhaling the drug via the nebuliser, and dismantling and cleaning equipment following dosing.

\section{Problems in setting up the nebuliser}

\section{Assembling components of the nebuliser system}

Patients are required to set up their nebuliser system, comprising: a nebuliser chamber, medication, accessories (facemask or mouthpiece), tubing and a compressor. Eleven patients revealed that their nebuliser system was assembled at all times (even when not in use), so that they were not required to assemble parts for each use. The most common reasons for this were limited 
Table 1 Problems encountered by patients using nebuliser therapy in the management of chronic obstructive pulmonary disease

\begin{tabular}{|c|c|c|}
\hline Theme & Description of step performed incorrectly & $\begin{array}{l}\mathrm{N} \\
(50)\end{array}$ \\
\hline \multirow{7}{*}{$\begin{array}{l}\text { Assembling and } \\
\text { operating }\end{array}$} & Failure to remove the nebuliser cap from the medication tank ${ }^{*}$ & 11 \\
\hline & Failure to ensure the vaporiser head is freely moving prior to filling the drug fluid* & 22 \\
\hline & Failure to reinsert the vaporiser head in the medication tank ${ }^{\star \star}$ & 3 \\
\hline & Failure to reconnect the nebuliser cap to the medication tank ${ }^{*}$ & 1 \\
\hline & Failure to fit the facemask/mouthpiece on the nebuliser cap* & 4 \\
\hline & $\begin{array}{l}\text { Failure to connect the tubing to the medication tank from one end and to the } \\
\text { compressor from the other* }\end{array}$ & 6 \\
\hline & Failure to switch on the compressor & 0 \\
\hline \multirow[t]{6}{*}{ Filling drug fluid } & Failure to store the nebuliser fluid correctly & 0 \\
\hline & Failure to use the nebuliser fluid at room temperature & 0 \\
\hline & Failure to prepare the nebuliser fluid immediately prior to use & 3 \\
\hline & Failure to dilute the nebuliser fluid* & 0 \\
\hline & Failure to mix the drug formulations & 0 \\
\hline & Failure to fill the medication tank with the drug fluid* & 6 \\
\hline \multirow[t]{3}{*}{ Compatibility } & Failure to use the correct nebuliser for the drug* & 0 \\
\hline & Failure to use the correct nebuliser for the compressor? & 25 \\
\hline & Failure to use compatible drug formulations* & \\
\hline $\begin{array}{l}\text { Patient/device } \\
\text { interface }\end{array}$ & Failure to fit the facemask/holds the mouthpiece* & 6 \\
\hline \multirow[t]{2}{*}{ Inhalation technique } & Failure to sit in an upright position* & 2 \\
\hline & Failure to inhale from the mouth* & 17 \\
\hline \multirow[t]{3}{*}{ Breathing pattern } & Failure to inhale slowly* & 23 \\
\hline & Failure to inhale as deeply as possible* & 28 \\
\hline & Failure to hold breath for few seconds before exhaling* & 39 \\
\hline End point & Failure to define an end point to stop nebulisation & 5 \\
\hline \multirow[t]{3}{*}{ Dismantling } & Failure to switch off the compressor & 0 \\
\hline & Failure to detach the nebuliser from the tubing & 9 \\
\hline & Failure to dismantle the nebuliser (cap/medication tank/vaporiser head) & 14 \\
\hline \multirow[t]{8}{*}{ Cleaning } & Failure to wash hands before handling the drug & 45 \\
\hline & Failure to run the machine for some time with saline/empty* & 44 \\
\hline & Failure to rinse the parts (except the tubing) under hot water after use* & 31 \\
\hline & $\begin{array}{l}\text { Failure to disinfect the parts (except the tubing) with a suitable disinfectant once a } \\
\text { day }^{*}\end{array}$ & 46 \\
\hline & Failure to wipe the compressor and tubing at least once a day with a damp cloth & 34 \\
\hline & Failure to discard the remaining drug fluid ${ }^{*}$ & 16 \\
\hline & $\begin{array}{l}\text { Failure to reassemble and place the nebuliser in a clean bag/tubing placed inside } \\
\text { compartment }\end{array}$ & 28 \\
\hline & Failure to close the lid when not in use & 15 \\
\hline \multirow[t]{3}{*}{ Drying } & Failure to leave the parts to dry on a clean tissue & 20 \\
\hline & Failure to run the machine until no moisture remains in the tubing & 42 \\
\hline & Failure to hang the tubing to dry & 32 \\
\hline \multirow[t]{2}{*}{ Equipment misuse } & Failure to place the equipment on a flat surface & 16 \\
\hline & Failure to place the equipment at least 4 inches away from any other equipment & 27 \\
\hline \multirow[t]{5}{*}{ Maintenance } & Failure to replace the tubing according to manufacturer's recommendations* & 36 \\
\hline & Failure to replace the nebuliser according to manufacturer's recommendations* & 37 \\
\hline & $\begin{array}{l}\text { Failure to replace the facemask/mouthpiece according to manufacturer's } \\
\text { recommendations* }\end{array}$ & 36 \\
\hline & $\begin{array}{l}\text { Failure to check the filter monthly and to replace it according to manufacturer's } \\
\text { recommendations* }\end{array}$ & 37 \\
\hline & Failure to service the equipment annually and to check it for any electrical fault* & 39 \\
\hline
\end{tabular}

Steps highlighted in bold are likely to result in either a reduced drug output $(*)$, no drug output $\left(^{* \star}\right)$ or an unknown drug output (?), if performed incorrectly by the patient.

manual dexterity and the unpredictable pattern of disease flare ups. These patients regarded themselves as having control over their condition: having the nebuliser set up eliminated panicking during the onset of attacks by ensuring medication could be administered quickly. 
I leave it plugged in, because the point is, when you do need it, you probably, to help not panic the best thing is to get it going as soon as possible. So next to that chair, I've actually got the nebules, and that's already set up, and is there, and with very little movement I can get it. I sit in the chair, pull the top off, and squirt the thing [nebule] in... (Participant 37, nebuliser user for 10 years)

When nebulisation was required, these patients filled the medication tank either by removing the nebuliser cap $(n=6)$, or through the opening in the facemask $(n=5)$. The latter, regarded by some patients as more convenient than unscrewing the cap, was justified by explaining that the medication ends up in the reservoir.

All but three patients failed to ensure that the vaporiser head/baffles was freely moving prior to filling the drug fluid $(n=47)$. This may mean the part not rotating freely, potentially affecting vapour output and properties of the emitted aerosol. Those who had their nebuliser set up at all times adopted inadequate cleaning procedures, and the vaporiser head was frequently found to be stuck and/or not rotating when the compressor was started. Even when the patients assembled the nebuliser prior to each use $(n=39)$, all but three failed to ensure that the vaporiser head moved freely, either not understanding this part's function, or not knowing it was detachable. In one case, the patient thought it should be tight fitting.

I use one ampoule and then I put it in there tighten that (the vaporiser head), it has to be secure, then put that back on (the nebuliser cap) and then I use the mask... (Participant 44, nebuliser user for 3 years)

Three patients described instances where they forgot to replace the vaporiser head in the chamber, while only three clearly understood the importance of this part being freely moving:

If anything goes wrong, I would think the piece to go wrong would be here [vaporiser head], although it would fail to vaporise and you wouldn't get anything out of here. Well you would, but it wouldn't be any good...

(Participant 7, nebuliser user for 6 months)

With regard to connecting the tubing to the compressor or nebuliser, difficulties arose due to poor manual dexterity and poor grip $(n=6)$. As a result, some patients had to rely on help from a carer.

No patients experienced problems with operating the compressor (plugging it into the mains and/or pressing the power button).

\section{Filling nebuliser fluid}

All but three patients prepared drug fluid immediately prior to use. Six patients reported experiencing problems with this step. Two reasons were identified: confusion about which product/formulation to use, and the physical and functional limitations of the patient (poor grip and eyesight). In these cases, patients relied on carers for assistance. Difficulties were described in opening medication vials (nebules): one patient commented on the difficulty of opening some vials, but not others.

Some of them I find quite difficult to twist to separate... I've had ones that are quite difficult, that I have to go off and get help; these are easy... (Participant 13, nebuliser user for 10 years)

\section{Diluting the nebuliser fluid}

Diluting drug fluid increases the volume nebulised, increasing drug output for a fixed residual volume and increasing duration of nebulisation.

One patient reported only sometimes diluting the drug formulation, and did not know why dilution was required. He described being confused that dilution was not carried out in hospital and was uncertain about the amount of saline to be used for dilution.

They're a big tube (saline) and you take it by injection $2 \mathrm{ml}$ or $2.5 \mathrm{ml}$ and put it in there (the chamber) and use it. But I have no idea why it is this amount, no idea, even the doctor never told me. (Participant 24, nebuliser user for 6 months)

One patient thought the dilution was to mask the taste of her medication, while another was substituting saline with distilled or boiled water. A further patient was using expired saline vials. This patient did not feel this was problematic as they were sealed, and she was considering using an irrigation solution (prescribed for her leg wound) in her nebuliser.

\section{Problems occurring during inhalation of the nebulised dose \\ The patient/device interface}

Forty patients were using facemasks; 10 used mouthpieces. Six patients experienced problems fitting their facemask: two attached the mask to the nebuliser inverted, and consequently could not fit it properly on their face. Three patients held the facemask with their hand instead of fastening it securely to the face. Holding was considered easier in one case, while two patients were using facemasks missing an elasticated band, which secures the mask to the head. This band was overstretched in another case, and one patient was using safety pins to repair an overstretched band and secure the mask to his face.

In terms of patient preference, five patients preferred a mouthpiece due to its relative ease of use and the ability to synchronise their breathing with aerosol output compared with the facemask.

I find even the oxygen's a menace, because you can't control it. What happens is it's pumping into your mouth all the time, whereby with this you are breathing it in and out. This one [mouthpiece] you can control; the 
facemask you can't. And it's the same with the oxygen. You can't control the oxygen. (Participant 8, nebuliser user for 15 years)

Six patients preferred a facemask, giving similar reasons, including that they felt more secure with the mask on and that it allowed for a more natural breathing pattern.

I just feel more secure with it over [the face]. I just didn't feel as though it [mouthpiece] was doing me any good at all, just in the mouth. (Participant 2, nebuliser user for 1 year)

\section{Leakage of drug fluid}

Some patients described fluid leakage during nebulisation, reducing the amount available for inhalation. Leakage occurred at the medication chamber/tubing junction $(n=3)$ due to overstretched tubing, or at the medication chamber/cap joint $(n=3)$ due to a cracked nebuliser cap or incorrect assembling of the parts.

Well, it tends to stretch at the end [tubing] and it goes too far, do you know what I mean, onto the chamber so you get a leakage. (Participant 49, nebuliser user for 3 years)

If you overtighten it [nebuliser cap], or once it's split, then while you're using it, it [fluid] tends to go over the top and run down and you end up with a pool on the floor and it's less efficient that way. (Participant 32, nebuliser user for 18 months)

Additionally, two patients described incidents of tubing 'popping off' the device during nebulisation, explainable in both cases by the use of overstretched tubing.

\section{Concerns about aerosol cloud safety and feeling claustrophobic}

Ill-fitting facemasks can result in drug deposition on the face and in the eyes causing adverse effects, which is a particular concern with inhaled steroids or for anticholinergic drugs prescribed for patients with glaucoma. Three participants expressed concerns about the safety of the aerosol depositing on the face and getting into the eyes.

I can't use a facemask...I use a mouthpiece...I was allergic and my eyes come up and my face comes up, so I use the mouthpiece. (Participant 43, nebuliser user for 10 years)

Another problem reported was feeling 'closed in' and claustrophobic with a facemask covering the entire face $(\mathrm{n}=3)$.

I didn't like using it [facemask] very much...I found it a bit claustrophobic on your face. (Participant 38, nebuliser user for 1 year)

\section{Inhalation technique and breathing pattern}

All but two patients reported sitting in an upright position during nebuliser use. Despite doing so, these patients did not have a clear understanding as to why this was important, other than it being more comfortable in this position. One patient described trying different manoeuvres to enhance inhaling the medication.

I tend to sit in an easy chair...because I am more relaxed, but as it comes towards the end there's more, you can get more by either sitting up, or even moving forward a bit. So initially I am very pleased to sit back and relax, and then move forward, because then it seems to be more effective to get it out. (Participant 37, nebuliser user for 10 years)

Only six patients who were using facemasks were breathing through their mouth, while the majority were either breathing through their nose $(n=17)$ or breathing through mouth and nose $(n=18)$. Clearly, patients who were using a mouthpiece should be breathing through their mouth. However, in one case, the patient was breathing nasally despite using a mouthpiece.

Only 12 participants reported breathing slowly. The patients explained that breathing at a slower rate is not always possible, especially when their chest is 'tight'.

The first couple of minutes you are gasping, so you are breathing fast, and then you've got to learn to regulate your breathing. That's what I've been trained to do by the physiotherapist, and the doctors. (Participant 23, nebuliser user for 4 years)

Several patients reported breathing deeply $(n=20)$. Although in most cases patients had not been instructed on breathing technique, they recognised the importance of deep breathing.

The other thing I try to do, normally, although I breathe normally, I do at the beginning try to breathe well out and take a very deep breath and hold on to it... Nobody ever said do so, it just seems to me that if you breathe very shallowly there's some part of the lung that isn't getting the medication, and it probably ought to. (Participant 37, nebuliser user for 10 years)

Holding the breath prior to exhalation was only performed by a few patients $(n=6)$. The majority reported experiencing difficulties with holding their breath, especially during severe attacks.

It depends if my chest is tight. If my chest is tight then I do [hold breath] momentarily, but I can't always hold it very long you know, so yes sometimes but not always. (Participant 28, nebuliser user for 10 years)

\section{Duration of nebulisation}

The duration of nebulisation ranged from 2 to $40 \mathrm{~min}$. Most commonly, participants reported a time between 10 and $15 \min (\mathrm{n}=21)$, with four reporting greater than 
20 min. Eight interrupted their nebulisation and resumed from $2 \mathrm{~h}$ to $24 \mathrm{~h}$ later. Interruption was mainly due to the inconvenience of long nebulisation sessions $(\mathrm{n}=3)$.

Other reasons for interruption were: coughing $(n=1)$, blocked nose $(n=1)$ and forgetting to return to the nebuliser after a temporary stop $(n=1)$.

Well, I tend to use it on and off rather than in one straight go because I find that after maybe a minute or half a minute using it, then I have to clear my throat and my nose because at the same time as the emphysema I suffer, my nose blocks up very quick which makes it difficult for breathing so until I clear my nose I can't clear my chest. So I have to use it in small doses probably over a 20 minute period. (Participant 32, nebuliser user for 18 months)

\section{Defining an end point of nebulisation}

The patients were asked to define the point at which they should end nebulisation. All but five patients defined an appropriate end point.

Because the fluid inside, it goes in here, because it throws it up all over the place, so if you knock it you'll get all the fluid down. So I knock it and knock it and knock it, hold it on one side, and if there's no fluid in the bottom I'm finished. If there's any fluid in the bottom I just keep doing it until it's all gone. (Participant 12 , nebuliser user for 20 years)

\section{Problems occurring after inhaling the nebulised dose}

The problems encountered by patients after inhalation related to dismantling, cleaning and maintenance.

\section{Dismantling the nebuliser}

After completing nebulisation, patients should switch off the compressor, then dismantle and clean the components of the nebuliser system. Fourteen patients did not dismantle their nebuliser after use. Most of them cleaned the nebuliser as a unit by running water through the opening of the mask or the nebuliser cap, shaking, and emptying out the water $(n=11)$. Manual dexterity was the commonest reason given by the patients for failing to dismantle the equipment.

I had terrible trouble because this (tubing) used to pop off. My hand wasn't strong enough to push it together and so now that's it on; I don't wash this at all. I found once it comes off, I find it hard to get back on. (Participant 16, nebuliser user for 10 years)

\section{Discarding residual liquid}

Any liquid remaining in the nebuliser should be discarded and never kept or reused. In most cases, patients stated that they nebulised until dryness and no residual volume remained in the chamber. Many patients reported not discarding any residual liquid $(n=16)$. Moreover, as previously described, some interrupted
Table 2 Frequency of cleaning nebuliser parts

\begin{tabular}{|c|c|c|c|}
\hline \multirow[b]{2}{*}{ Frequency } & \multicolumn{3}{|c|}{ Patients $(\mathrm{N}=50)$} \\
\hline & $\begin{array}{l}\text { Facemask/ } \\
\text { mouthpiece }\end{array}$ & Chambers & Tubing \\
\hline $\begin{array}{l}\text { After each } \\
\text { use }\end{array}$ & 19 & 20 & 18 \\
\hline Daily* & 10 & 7 & - \\
\hline $\begin{array}{l}\text { Alternate } \\
\text { days }\end{array}$ & 2 & 2 & - \\
\hline Twice weekly & 4 & 5 & - \\
\hline Weekly & 9 & 9 & - \\
\hline Monthly & 3 & 4 & - \\
\hline Never & 3 & 3 & 32 \\
\hline
\end{tabular}

nebulisation $(\mathrm{n}=8)$, resulting in use of medication present in the nebuliser chamber for up to $24 \mathrm{~h}$, which may affect drug formulation stability and can be a risk for contamination. In one case, the patient admitted reusing residual liquid although she recognised the importance of discarding it.

\section{Cleaning the nebuliser system}

After dismantling the nebuliser and discarding remaining liquid, patients/carers should follow the manufacturer's cleaning instructions. The majority of the patients did not adhere to good practice with regard to washing parts in warm soapy water after each use $(n=34$; tables 2 and 3), never disinfected nebuliser parts $(n=46$; table 3) and few ran the machine empty or with saline after use.

After cleaning, components should be allowed to dry naturally and stored in a clean bag. Tubing should be air

Table 3 Method of cleaning, sanitisation/'sterilisation' and drying nebuliser parts

\begin{tabular}{|c|c|}
\hline Method of cleaning & $\begin{array}{l}\text { Patients } \\
(\mathrm{N}=50)\end{array}$ \\
\hline Warm soapy water & 16 \\
\hline Tap water & 9 \\
\hline Warm water & 6 \\
\hline Cold water & 2 \\
\hline Hot water & 4 \\
\hline Boiling water & 4 \\
\hline Tissue & 3 \\
\hline \multicolumn{2}{|l|}{ Method of sanitisation/'sterilisation' } \\
\hline Boil & 2 \\
\hline Using lime scale tablets & 1 \\
\hline $\begin{array}{l}\text { Detergent or commercial disinfectant } \\
\text { solution }\end{array}$ & 1 \\
\hline \multicolumn{2}{|l|}{ Method of drying } \\
\hline With a cloth or tissue & 5 \\
\hline Drain it or leave it to dry naturally & 27 \\
\hline Blow it or air dry it with the compressor & 3 \\
\hline Never dried it before & 15 \\
\hline
\end{tabular}


blown with the compressor after each use to remove retained moisture. However, many patients never dried the parts after cleaning $(n=15$; table 3$)$, less than half stored nebuliser parts in a clean bag after use $(n=22)$ and few dried the tubing by compressor-air blowing $(\mathrm{n}=8)$.

And that's dry, but inside there, that is misty, inside, where the tube goes...You can blow it out with the nebuliser; you can blow it out and dry it with the nebuliser. (Participant 11, nebuliser user for 3 years)

As a result of inadequate cleaning, dirty masks $(n=12)$, medication chambers with evidence of crystallisation inside $(n=5)$, blocked tubing $(n=3)$ and stained compressors $(n=19)$ were observed by the researcher.

\section{Maintaining the nebuliser system}

Most nebuliser manufacturers recommend that facemasks/mouthpieces and tubing be replaced every 3 months with daily use, and the British Thoracic Society advises replacement of such parts at 3-6 monthly intervals. Disposable nebuliser chambers should be replaced every 3 months, while durable chambers can last up to a year if cleaned adequately. Filters should be checked monthly and replaced if discoloured, and the compressor should be serviced annually and checked for electrical faults.

The majority of the patients did not adhere to these recommendations (table 4), making their own judgements regarding the need for replacements.

Well I can't see the need to change it when it's working. (Participant 35, nebuliser user for 5 years)

I've never done the filters, I must admit. I've never bothered a great deal with them because there seems to be a flow you know, a good flow of air, but I realise that it should be something that I looked at, because I've got no instructions on the thing because it doesn't belong to me. (Participant 6, nebuliser user for 6 months)

As a result of inadequate maintenance, patients either overused some parts, or used damaged components, which may adversely affect therapy. Damaged or overused parts included: facemasks with overly stretched elasticated bands $(n=5)$, compressors with a broken lid $(n=2)$, cracked nebuliser caps $(n=2)$, damaged/discoloured tubing $(\mathrm{n}=13)$, damaged/discoloured mask $(n=5)$, damaged/discoloured chamber $(n=9)$ and discoloured filters $(\mathrm{n}=11)$.

Some patients repaired damaged items: repairing the compressor lid with string $(\mathrm{n}=1)$, adhesive tape around a cracked nebuliser cap or chamber $(n=2)$, cutting off damaged parts of tubing $(n=2)$ and using pins to secure elasticated bands of facemasks $(n=1)$. Wrapping tape around the nebuliser cap/chamber resulted in inadequate cleaning, cut tubing resulted in failure to connect properly to the compressor and using pins can result in an ill-fitting facemask. Additionally, there was evidence of poor equipment use: equipment not placed $10 \mathrm{~cm}$ from other objects $(\mathrm{n}=27)$, the compressor used on the floor/couch to minimise noise $(n=16)$, the compressor covered with a blanket during use $(n=3)$ and the compressor 'holed' to reduce operating noise $(n=1)$.

\section{Patients' reports of information received}

Thirty-one patients did not feel that they had been adequately informed regarding the use of nebuliser therapy. Twelve recalled receiving information only about dose frequency and seven remembered being informed about how to use and clean the nebuliser.

\section{DISCUSSION}

All participants in this study encountered problems with their nebulisers. Teale $e t a l^{13}$ estimated a $50 \%$ prevalence of problems with nebuliser use among elderly patients with COPD who were prescribed a nebuliser and recruited through a hospital, and who received comprehensive instruction on its use. However, the present study provides a more representative setting where most $(80 \%)$ of the patients acquired their nebuliser through a route other than the hospital, and most had received no instruction on its use.

Problems were reported with all aspects of nebuliser use, many of which could impact on clinical outcomes. For example, incorrectly assembling components such as an inverted facemask or a loosely fitted nebuliser cap is

Table 4 Frequency of replacing nebuliser parts and servicing the compressor

\begin{tabular}{|c|c|c|c|c|c|}
\hline \multirow[b]{2}{*}{ Frequency } & \multicolumn{5}{|l|}{ Patients $(\mathrm{N})^{\star}$} \\
\hline & Facemask/mouthpiece & Chambers & Tubing & Filter & Compressor \\
\hline Weekly & - & - & - & - & - \\
\hline Monthly & 2 & 2 & 2 & 2 & - \\
\hline 3 monthly & 6 & 5 & 4 & 3 & - \\
\hline 6 monthly & 4 & 4 & 3 & 1 & - \\
\hline Annually & 3 & 3 & 3 & - & 9 \\
\hline Discoloured/damaged & 10 & 9 & 13 & 11 & 2 \\
\hline Never & 24 & 26 & 21 & 31 & 39 \\
\hline
\end{tabular}

*One patient replaced all the parts after two or three uses, and one patient was using the nebuliser system without the outlet/inlet filter. 
likely to reduce the amount of drug reaching patients' lungs. In instances where the vaporiser head was missing, no aerosol would be produced during nebulisation. Failure to fit the facemask, or use the mouthpiece correctly, results in aerosol escaping to the surrounding atmosphere rather than entering the airways. An illfitting mask may also result in drug deposition on the patient's face or in the eyes, ${ }^{19}$ potentially causing adverse effects such as glaucoma. ${ }^{20} 21$ Preference for facemasks or mouthpieces varied between participants. To promote effective therapy, patients should be given the choice of interface that they find most comfortable and easy to use. Ideally, all patients supplied with a mouthpiece should keep a facemask in case of an emergency. Problems with manual dexterity, having a poor grip, difficulty opening vials and poor eyesight were contributory factors to problems for many patients.

Confusion about the amount of saline required to dilute drug formulations or use of other diluents was identified. Substituting isotonic saline with water is hazardous, producing hypotonic solutions that may cause bronchoconstriction. ${ }^{22}$ Moreover, there was considerable confusion regarding whether dilution was necessary.

This study has shown that patients had poor understanding of correct inhalation technique. Breathing technique is considered less critical for nebulisers compared with pMDIs or DPIs. COPD is characterised by airway constriction, resulting in limited aerosol deposition in the lungs and in particular into the smaller airways. ${ }^{23}$ Body posture can affect the area of drug deposition and trying out certain body manoeuvres can help in targeting poorly ventilated airways. There was uncertainty among patients in regard to achieving optimal efficacy. The majority of patients in this study were found to be nose breathing. Heyder et $a l^{24}$ determined that a larger amount of aerosol is needed to compensate for loss in the nose. Inhaling slowly and deeply through the mouth and breath holding for a few seconds (when possible) before exhalation can increase the amount of drug deposited in the airways by at least two-fold compared with normal tidal breathing. ${ }^{25}$ Although slow, deep breathing with breath holding may not always be possible, especially for patients with severe disease, such inhalation technique is beneficial whenever possible.

Patients in this study undertook inadequate cleaning and maintenance procedures. Previous studies have found problems with cleaning to be frequent. ${ }^{13}{ }^{18}$ Adherence to manufacturers' cleaning and maintenance instructions is essential for correct operation of the equipment. ${ }^{26}$ Most recommend cleaning parts after each use with warm soapy water, with disinfection/boiling at least weekly. Some recommend the nebuliser be run empty, or with saline, after use. Inadequate cleaning and drying affect nebuliser performance and can lead to subtherapeutic outcomes as well as being an infection risk. Inadequately cleaned and maintained nebulisers have been identified as potential reservoirs for serious pathogens, such as Pseudomonas spp, which may be delivered to the lung. ${ }^{27-29}$ The potential for occurrence of an exacerbation, and the need for strategies to improve adherence to nebuliser cleaning and sanitisation regimes are clear.

With regard to maintaining the nebuliser and compressor, the infrequent replacement of the disposable parts of the nebuliser system and lack of servicing have been previously documented. ${ }^{15} 1718$ Blockage of inlet filters and lack of servicing affect compressor performance. ${ }^{14}$ In this study, discoloured filters were observed and a lack of servicing of the compressor was especially prominent.

Strengths of this study are that it represents a comprehensive examination of the whole process of nebuliser use by using a structured observation to document practices combined with patients' own explanations of their experiences, concerns and rationale. While the study included patients from across 38 medical practices and intermediate care, it is limited in that it was undertaken in only one part of Greater London and may not reflect provision and support elsewhere.

Nebulisers remain an important part of therapy for many patients with COPD, including those with severe disease. However, this study has identified that participants experienced difficulties with all aspects of nebuliser use and devised strategies to overcome these, many of which would be anticipated to have an impact on clinical outcomes and potentially contribute to treatment failures. They described a service which did not always meet their needs in terms of supply and maintenance of equipment and associated support. Ensuring appropriate systems, services and support for these patients should be a priority for healthcare providers if optimal outcomes from medication are to be achieved, reducing disease burden for patients and promoting cost-effective care.

Acknowledgements The authors appreciate the contribution of collaborators from Harrow Primary Care Trust: Mrs Uma Bhatt, Mrs Meena Sethi and Ms Zinat Rajan for help with conducting the study and for facilitating data collection. They acknowledge the assistance of staff in all practices with the identification and recruitment of eligible participants, and also thank all patients for their participation.

Contributors All authors were responsible for the design and planning of the study, contributed to writing of the manuscript and gave approval of the drafts. BA FJS, TR and KMGT undertook data collection and analysis. KMGT and FJS are responsible for the overall content as guarantors for the manuscript.

Funding This study was funded by the Public Authority for Applied Education and Training, Kuwait.

Competing interests None.

Ethics approval This study was granted ethical approval from Harrow Research Ethics Committee on 11 November 2008, REC reference 08/H0719/ 55 .

Provenance and peer review Not commissioned; externally peer reviewed.

Data sharing statement No additional data are available.

Open Access This is an Open Access article distributed in accordance with the Creative Commons Attribution Non Commercial (CC BY-NC 4.0) license, 
which permits others to distribute, remix, adapt, build upon this work noncommercially, and license their derivative works on different terms, provided the original work is properly cited and the use is non-commercial. See: http:// creativecommons.org/licenses/by-nc/4.0/

\section{REFERENCES}

1. O'Driscoll R. Home nebulized therapy: is it effective? Respir Med 1991:85:1-3.

2. Jarvis S, Ind PW, Shiner RJ. Inhaled therapy in elderly COPD patients: time for re-evaluation? Age Ageing 2007;36:213-18.

3. O'Driscoll BR, Kay EA, Taylor RJ, et al. A long-term prospective assessment of home nebulizer treatment. Respir Med 1992:86:317-25.

4. Bosley CM, Corden ZM, Rees PJ, et al. Psychological factors associated with use of home nebulized therapy for COPD. Eur Respir J 1996;9:2346-50.

5. Corden ZM, Bosley CM, Rees PJ, et al. Home nebulized therapy for patients with COPD: patient compliance with treatment and its relation to quality of life. Chest 1997;112:1278-82.

6. Osman IM, Godden DJ, Friend JA, et al. Quality of life and hospital re-admission in patients with chronic obstructive pulmonary disease. Thorax 1997;52:67-71.

7. Stevens N. Inhaler devices for asthma and COPD: choice and technique. Prof Nurse 2003;18:641-5.

8. Abley C. Teaching elderly patients how to use inhalers: a study to evaluate an education programme on inhaler technique for elderly patients. J Adv Nurs 1997;25;699-708.

9. Johnson DH, Robart P. Inhaler technique of outpatients in the home. Respir Care 2000;45;1182-7.

10. Coakley AL. Helping patients to master correct inhaler techniques: nursing role. Br J Nurs 2001;10:424-8.

11. Molimard M, Raherison C, Lignot S, et al. Assessment of handling of inhaler devices in real life: an observational study in 3811 patients in primary care. J Aerosol Med 2003;16:249-54.

12. Ho SF, Omahony MS, Steward JA, et al. Inhaler technique in older people in the community. Age Ageing 2004;33:185-8.

13. Teale $\mathrm{C}$, Jones A, Patterson CJ, et al. Community survey of home nebulizer technique by elderly people. Age Ageing 1995;24:276-7.
14. Godden DJ, Robertson A, Currie N, et al. Domiciliary nebuliser therapy: a valuable option in chronic asthma and chronic obstructive pulmonary disease. Scott Med J 1998;43:48-51.

15. Murphy D, Holgate ST. The use and misuse of domiciliary nebulizer therapy on the Isle of Wight. Respir Med 1989;83:349-52.

16. Mansfield K. Evaluating a nebuliser service to improve patient care. Nurs Times 1996;92:27-9.

17. Melani AS, Sestini P, Aiolfi S, et al. GENebu Project: home nebulizer use and maintenance in Italy. Eur Respir J 2001;18:758-63.

18. Boyter AC, Carter R. How do patients use their nebuliser in the community? Respir Med 2005;99:1413-17.

19. Sangwan S, Gurses BK, Smaldone GC. Facemasks and facial deposition of aerosols. Pediatr Pulmonol 2004; 37:447-52.

20. Mulpeter KM, Walsh JB, O'Connor M, et al. Ocular hazards of nebulized bronchodilators. Postgrad Med J 1992;68:132-3.

21. Hall SK. Acute angle-closure glaucoma as a complication of combined beta-agonist and ipratropium bromide therapy in the emergency department. Ann Emerg Med 1994;23:884-7.

22. Mann JS, Howarth PH, Holgate ST. Bronchoconstriction induced by ipratropium bromide in asthma: relation to hypotonicity. $\mathrm{Br} \mathrm{Med} \mathrm{J}$ (Clin Res Ed) 1984;289:469.

23. Lin MS, Goodwin DA. Pulmonary distribution of an inhaled radioaerosol in obstructive pulmonary disease. Radiology 1976;118:645-51.

24. Heyder J, Gebhart J, Rudolf G, et al. Deposition of particles in the human respiratory tract in the size range $0.005-15 \mu \mathrm{m}$. J Aerosol Sci $1986 ; 17: 811-25$.

25. Smaldone GC. Smart nebulizers. Respir Care 2002;47:1434-41.

26. Wilson RS, Muers MF. Running a domiciliary nebuliser service. Thorax 1997;52(Suppl 2):S104-6.

27. Cohen HA, Kahan E, Cohen Z, et al. Microbial colonization of nebulizers used by asthmatic children. Paediatr Int 2006:48:454-8.

28. Blau $\mathrm{H}$, Mussaffi $\mathrm{H}$, Mei Zahav M, et al. Microbial contamination of nebulizers in the home treatment of cystic fibrosis. Child Care Health Dev 2007;33:491-5.

29. Jarvis S, Ind PW, Thomas C, et al. Microbial contamination of domiciliary nebulisers and clinical implications in chronic obstructive pulmonary disease. BMJ Open Respir Res 2014;1:e00018. 